\title{
A Fatal Complication of Dermatomyositis: Spontaneous Pneumomediastinum
}

\author{
Ezgi Demirdöğen Çetinoğluㄹ, Ediz Dalkılıç², Muharrem Erol ${ }^{3}$, Nilüfer Aylin Acet ${ }^{1}$, \\ Ahmet Ursavaş̧ ${ }^{1}$ Ercüment Ege ${ }^{1}$
}

${ }^{1}$ Department of Chest Diseases, Uludağ University School of Medicine, Bursa, Turkey

${ }^{2}$ Department of Internal Diseases, Division of Romatology, Uludağ University School of Medicine, Bursa, Turkey

${ }^{3}$ Department of Chest Surgery, Uludağ University School of Medicine, Bursa, Turkey

\begin{abstract}
Interstitial lung disease (ILD) is a negative prognostic factor associated with increased morbidity and mortality in patients with dermatomyositis (DM). Spontaneous pneumomediastinum is a rare complication of DM and it can be fatal. We present a 48-year-old woman with DM and ILD complicated by pneumomediastinum without pneumothorax and subcutaneous emphysema.
\end{abstract}

Keywords: Dermatomyositis, immunosuppressive therapy, interstitial lung disease, spontaneous pneumomediastinum

\begin{abstract}
Keywords: Dermatomyositis, immunosuppressive therapy, interstitial lung disease, spontaneous pneumomediastinum
\section{INTRODUCTION}

Dermatomyositis (DM) is a systemic inflammatory myopathy that occurs primarily during childhood and between $40-50$ years of age, involving the heart, gastrointestinal tract, lungs, and skin. DM is a vasculopathy, characterized by the deposition of immune complexes within blood vessels. It is also characterized by symmetric proximal muscle weakness and elevated serum skeletal muscle enzyme levels as well as elevated levels of serum glutamate oxaloacetate (SGOT), serum pyruvate transaminase (SGPT), and lactate dehydrogenase (LDH). Other phenomena associated with the disease include not only skin lesions typical for DM but also myopathic changes noted on electromyography (EMG), evidence of muscle degeneration, regeneration abnormalities, necrosis, phagocytosis, and the presence of an interstitial mononuclear infiltrate; all of which may be noted on muscle biopsy. Interstitial lung disease (ILD) is a negative prognostic factor associated with increased morbidity and mortality in patients with DM (1). Glucocorticoid treatment responses were better in anti-Jo-1 antibody-positive patients, which indicate a favorable prognosis for the said patients (2).

Spontaneous pneumomediastinum is characterized by the appearance of free air in the mediastinum not preceded by trauma, surgery, or other medical procedures. Spontaneous pneumomediastinum is a rare complication of DM and may be fatal. (3) We herein present a rare case involving a patient with DM and ILD complicated by pneumomediastinum without pneumothorax and subcutaneous emphysema.
\end{abstract}

Received Date: 12.11 .2014 Accepted Date: 14.11.2015 Available Online Date: 11.01 .2016

DOI: 10.5152/ejp.2015.65265

Correponding Author Ezgi Demirdöğen Çetinoğlu E-mail: demirdogenezgi@gmail.com

- Available online at www.eurasianjpulmonol.com Commons Attribution-NonCommerci 4.0 International License.

\section{CASE PRESENTATION}

A 48-year-old woman was admitted to the rheumatology department of a tertiary hospital with proximal muscle weakness, myalgia, weight loss, fever, hoarseness, exertional dyspnea, and polyarthralgia. Her symptoms started one month before she was admitted to the hospital. On physical examination, she exhibited skin ulcerations on her hands and Gottron's papules over the bilateral metacarpophalangeal and interphalangeal joints. She also had cellophane crackles in the lower lung fields bilaterally and proximal muscle weakness in her lower extremities (4/5). Myopathic abnormalities in the proximal muscles of the lower extremities were observed on EMG. Initial laboratory tests showed that SGOT (117 U/L), SGPT (51 U/L), LDH (499 IU/L), and creatine kinase (CK) (315 IU/L) levels were ele- 

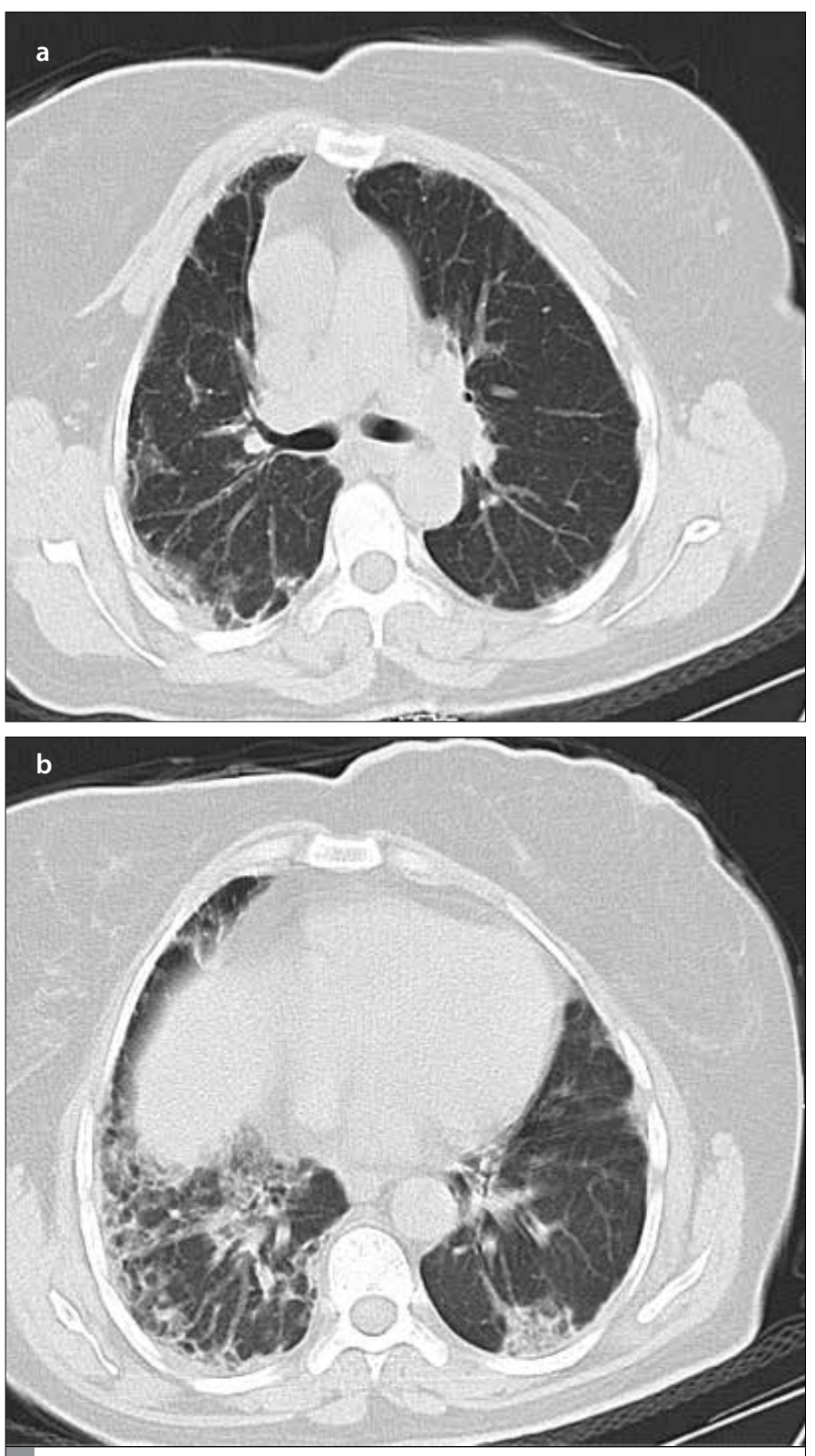

Figure 1. a, b. Thoracic CT performed upon the patient's initial presentation for DM-ILD did not demonstrate any air in the mediastinum (a), primarily subpleural distribution of honeycombing as well as focal consolidation and ground glass opacities in the lower lung fields (b)

CT: Computed thomography; DM: dermatomyositis; ILD: interstitial lung disease

vated. Her C-reactive protein $(0.8 \mathrm{mg} / \mathrm{dL})$ and sedimentation rate (44 $\mathrm{mm} / \mathrm{h}$ ) were each slightly increased. HBs antigen, anti-HBs, and anti-HCV antibody tests were negative. The anti-nuclear antibody (ANA) test was positive at 1/100; an anti-centromere $B$ antibody test was also positive. Other antibody tests, including double-stranded DNA, anti-Smith, anti-Ro (SSA), anti-La (SSB), Jo-1, Scl-70, anti-neutrophil cytoplasmic antibody, and rheumatoid factor (RF), were negative. Pulmonary function tests were consistent with restrictive respiratory failure (forced vital capacity: $1.25 \mathrm{~L}, 42 \%$, forced expiratory volume at $1 \mathrm{~s} /$ forced vital capacity; $80 \%$ of predicted). A chest X-ray showed infiltrative opacities in both lung bases. Thoracic computed thomography $(\mathrm{CT})$ showed patchy ground glass attenuation and reticular
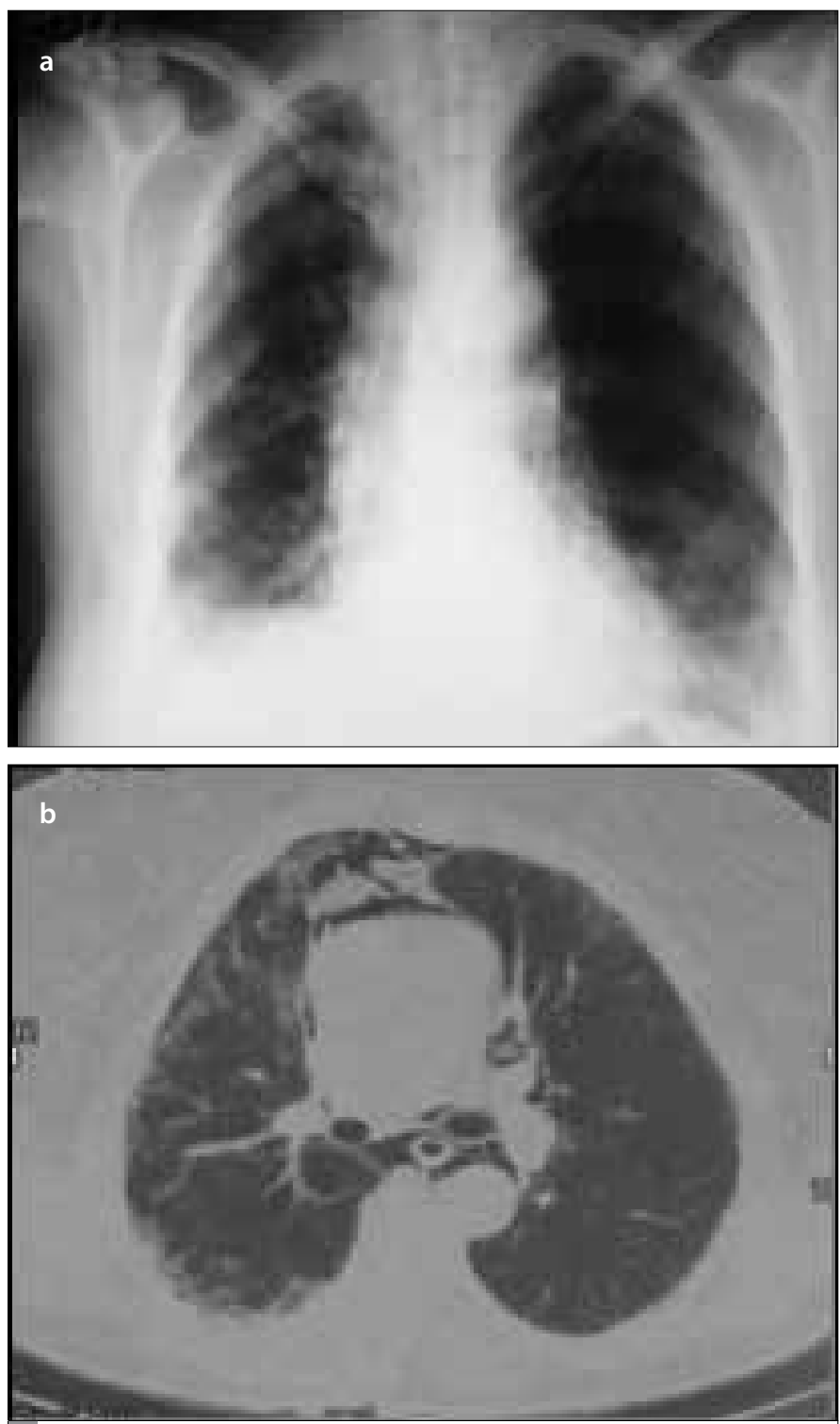

Figure 2. a, b. Chest X-ray: Free air around the right paratracheal area, reticular opacities in both lower lung fields, and volume loss in the right hemithorax (a), thoracic CT: Free air in the upper mediastinal area (b)

CT: Computed thomography

linear opacities in the lower lobes bilaterally as well as subpleural honeycombing (Figure 1a, b). She was diagnosed with DM and ILD. Pulse methylprednisolone ( $1 \mathrm{~g} / \mathrm{d}$ for 3 days) and cyclophosphamide (CYC, $1 \mathrm{~g} / \mathrm{d}$ for 3 days) were started. The patient's skin, muscle, and respiratory symptoms subsequently improved. Maintenance therapy with methylprednisolone $(60 \mathrm{mg} / \mathrm{d}$ for 4 weeks, $50 \mathrm{mg} / \mathrm{d}$ for 4 weeks, $45 \mathrm{mg} / \mathrm{d}$ for 2 weeks, followed by $5 \mathrm{mg} / \mathrm{d}$ tapers each week) and hydroxychloroquine sulfate $(200 \mathrm{mg} / \mathrm{d})$ was initiated. After 4 weeks, treatment with CYC was planned. Her CK levels gradually decreased and her ILD stabilized. However, during the first month of the treatment ( 3 months after the onset of symptoms), she presented to the emergency department with progressively worsening dyspnea. On physical examination, her body temperature was $36.4^{\circ} \mathrm{C}$ and her pulse rate was 120 beats/min. Her blood pressure was 120/70 mmHg and her respiratory rate was 28 breaths/min. There were fine crackles in both the lungs. An arterial blood gas drawn with the patient at rest 

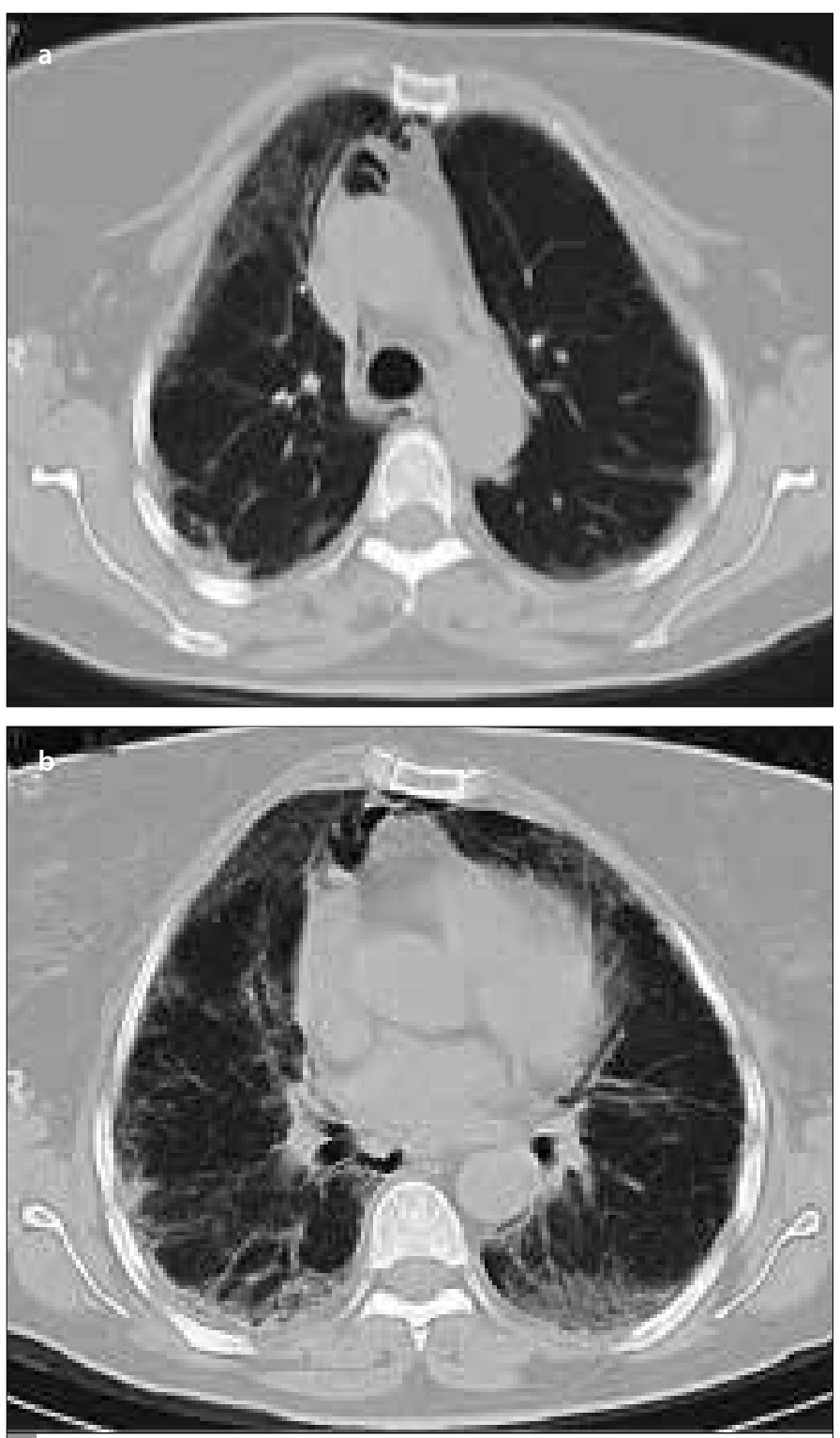

Figure 3. a, b. Thoracic CT: One month following the patient's initial presentation with DM-ILD, a CT scan demonstrated improvements in her pulmonary infiltrates and showed pneumomediastinum (a), thoracic CT: One month following the patient's initial presentation, a CT scan showed improvement in both basal area (b)

CT: Computed thomography; DM: dermatomyositis; ILD: interstitial lung disease

revealed the following: $\mathrm{PO}_{2} 65 \mathrm{mmHg}, \mathrm{PCO}_{2} 30.5 \mathrm{mmHg}$, and $\mathrm{pH} 7.44$. Her SGOT (110 IU/L), SGPT (194 IU/L), LDH (585 IU/L), and GGT (713 IU/L) levels were increased; however, her CK (30 IU/L) level was normal. The sedimentation rate was $24 \mathrm{~mm} / \mathrm{h}$ and C-reactive protein level was $0.29 \mathrm{mg} / \mathrm{dL}$; both of which were within normal limits. A chest X-ray (Figure 2a) and chest CT (Figure 2b) demonstrated pneumomediastinum without subcutaneous emphysema or pneumothorax. Comparisons with the prior chest $\mathrm{CT}$ did not reveal progression of any interstitial densities or worsening of sub pleural honeycombing (Figure 2a, b, 3a, b). The patient was hospitalized with a sudden onset of pneumomediastinum. Minimal improvement was noted with bed rest and oxygen administration over the following two weeks. However, her pneumomediastinum began to show signs of worsening following this period (Figure 4). Pulse methylprednisolone (1

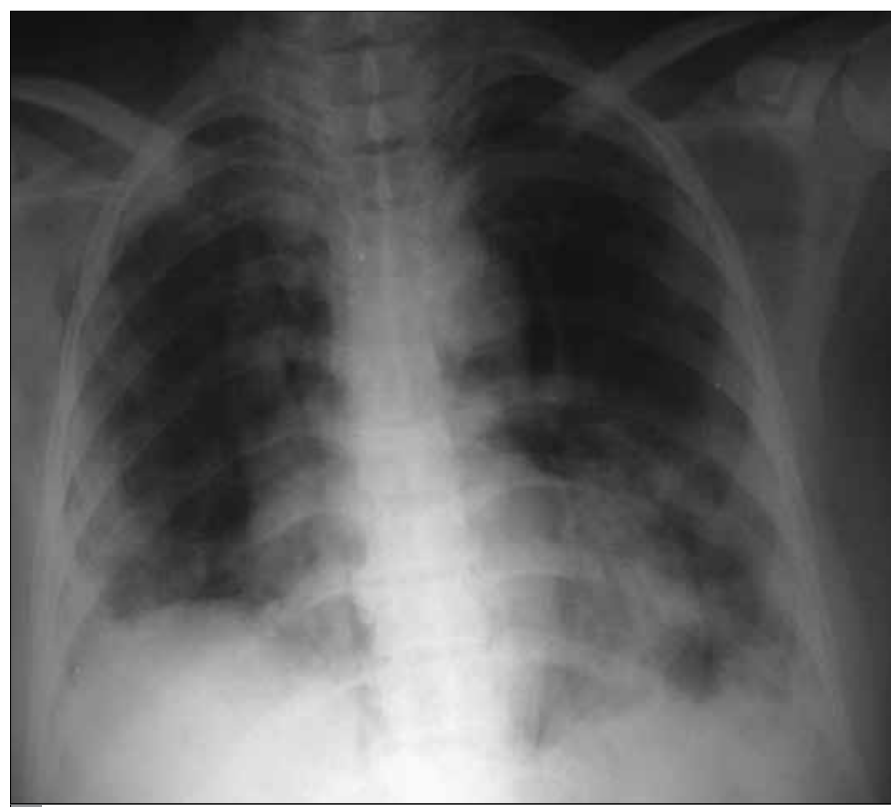

Figure 4. Chest X-ray demonstrated progression of free air in mediastinal area

$\mathrm{g} / \mathrm{d}$ for 3 days) and CYC ( $1 \mathrm{~g} / \mathrm{d}$ ) were subsequently administered. She was intubated for rapid progression of her pneumomediastinum and respiratory failure but passed away on the fifth day following intubation. Verbal informed consent was obtained from the patients' family after she died.

\section{DISCUSSION}

We herein described a rare case involving a patient with DM and ILD complicated by pneumomediastinum without pneumothorax and subcutaneous emphysema. In this case, we observed that the patient's interstitial densities were not increased following the detection of the pneumomediastinum with ILD, which was treated with corticosteroid and immunosuppressive agents. DM is an inflammatory myopathy that most often results in ILD. Poor prognostic factors in the setting of DM- or polymyositis-associated ILD include acute interstitial pneumonia, neutrophilic alveolitis on bronchoalveolar lavage, low forced vital capacity $(<60-65 \%)$, and diffuse alveolar damage on histological examination $(4,5)$. There was no relationship between muscle-skin involvement, CK levels, ANA results, RF results, and ILD in DM.

Le Goff et al. (6) reported that the prevalence of pneumomediastinum in myositis is approximately $2.2 \%$. In most cases, pneumomediastinum occurs within the first year of DM onset or polymyositis symptoms. DM and polymyositis are common in women, but myositis complicated by pneumomediastinum appears to be more common in men. Most cases of pneumomediastinum associated with connective tissue diseases were attributed to DM in a recent review. The overall mortality rate noted by this review was $34 \%$, whereas $25 \%$ of deaths were attributed to respiratory distress. Poor prognostic factors included the absence of muscle weakness, decreased vital capacity, and carbon monoxide diffusing capacity prior to the development of pneumomediastinum and high-dose corticosteroid treatment (6, 7). On the other hand, lyer et al. (3) found that patients with spontaneous pneumomediastinum most commonly had ILD as a pre-existing lung disease. Pneumomediastinum has been linked to DM more frequently than it has been to any other autoimmune disease $(8,9)$. Although the mechanism underlying this phenomenon is not clear, it 
has been suggested that sub pleural cyst ruptures due to interstitial fibrosis, cutaneous vasculopathies, bronchial necrosis secondary to these vasculopathies, and glucocorticoid effects on weakened pulmonary interstitial tissue may play a role (10-12). Neves Fde et al. (13) observed that the occurrence of spontaneous pneumomediastinum in a DM setting is particularly common in young patients because of vasculitic activity. Ma et al. (14) suggest that an inflammatory process involving endothelial cells and/or the coagulation-fibrinolytic system may play a role in the pathogenesis of pneumomediastinum in patients with DM. Cicuttini and Fraser (10) put forward that the development of pneumothorax and/or pneumomediastinum probably depends on the location of the rupture (peripheral for pneumothorax and adjacent to vessels for pneumomediastinum) with the air spreading in the peribronchial and perivascular spaces in the mediastinum. From this point of view, we thought that the possible mechanism of pneumomediastinum in our case was cutaneous vasculopathy. In a retrospective study, 19 of 28 connective tissue disease patients complicated with pneumomediastinum had subcutaneous emphysema and six of them had pneumothorax (15).

Korkmaz et al. (7) suggested that younger patients with skin lesions consistent with DM, muscular involvement, normal or slightly elevated CK levels, ILD, and a history of corticosteroid treatment should be monitored carefully for the development of pneumomediastinum, as was noted by our group. Our patient had these risk factors, including ILD, decreased vital capacity, negative anti-Jo-1 antibody results, signs of active cutaneous vasculopathy, and treatment with high-dose glucocorticoids for DM. Patients with DM and spontaneous pneumomediastinum may be classified into two groups. The first group includes patients with severe ILD who suffer from high mortality. The second group presents with vasculopathy findings but does not have ILD; therefore, this group has better prognosis $(9,16)$. Our patient was categorized in the first group. Pneumomediastinum without ILD has better prognosis.

Matsuoka et al. (17) described significant decrease in the extent of opacification in patients who received either corticosteroids or immunosuppressive agents for ILD at the time their pneumomediastinums were detected when the $\mathrm{CT}$ images were compared with CT images taken before these patients developed pneumomediastinum. Progressions of honeycombing scores were not evident in our case when pneumomediastinum was diagnosed. When ILD and respiratory failure progress, pulse corticosteroid therapy may be needed as pulse corticosteroid therapy or increased doses of corticosteroids may be detrimental to the course of the disease (11). One open-label study suggested that CYC (IV) is a safe and effective treatment for PM- or DM-associated interstitial pneumonia. The combination of pulse-dosed CYC and corticosteroids in 17 refractory patients resulted in significantly improved dyspnea, vital capacities, and CT findings. The results of the trial in question suggest that CYC (IV) can be more effective during the early stages of the disease (18). In addition, early initiation of immunosuppressive agents (within 1 month of steroid therapy) is one of the predictive factor for better prognosis for the patients with DM complicated pnemomediastinum (15). Ma et al. (14) hypothesized that medication targeted to endothelial cells and/or the coagulation-fibrinolytic system may be useful for these patients. Treatment for spontaneous pneumomediastinum is not specific, and it involves careful observation, bed rest, oxygen inhalation, and treatment with analgesics (19). In patients with connective tissue disease-associated ILD, the risk of surgery must be taken into account.

\section{CONCLUSION}

We herein present a rare case involving a patient with DM and ILD complicated by pneumomediastinum. The mechanism underlying spontaneous pneumomediastinum in patients with DM remains unclear. Corticosteroids and immunosuppressive treatments should be introduced rapidly, particularly if factors associated with a poor prognosis are present. In addition, following the onset of pneumomediastinum with ILD, either pulse corticosteroid therapy or increased doses of corticosteroid should be administered prudently because of the weakened effect on interstitial lung tissue.

Informed Consent: Verbal informed consent was obtained from patients' family who participated in this case.

Peer-review: Externally peer-reviewed.

Author contributions: Concept - E.D.Ç.,N.A.A., A.U., E.D., M.E.; Design - E.D.Ç., N.A.A., A.U., M.E., E.E.; Supervision - E.D.Ç., E.E., A.U., M.E., N.A.A., E.D.; Resources - N.A.A., E.D.Ç.; Materials - E.D.Ç., N.A.A.; Data Collection and/or Processing -E.D.Ç., A.U., E.D.; Analysis and/or Interpretation - E.D.Ç., A.U.; Literature Search - E.D.Ç., E.E.; Writing Manuscript - E.D.Ç., A.U.; Critical Review - E.D.Ç., A.U.

Conflict of Interest: No conflict of interest was declared by the authors.

Financial Disclosure: The authors declared that this study has received no financial support.

\section{REFERENCES}

1. Marie I, Hachulla E, Cherin P, Dominique S, Hatron PY, Hellot. MF, et al. Interstitial lung disease in polymyositis and dermatomyositis. Arthritis Rheum 2002; 47: 614-22. [CrossRef]

2. Kunimasa K, Arita M, Nakazawa T, Tanaka M, Tsubouchi K, Konishi S, et al. The clinical characteristics of two anti-OJ (anti-isoleucyl-tRNA synthetase) autoantibody-positive interstitial lung disease patients with polymyositis/dermatomyositis. Intern Med 2012; 51: 3405-10. [CrossRef]

3. lyer VN, Joshi AY, Ryu JH. Spontaneous pneumomediastinum: analysis of 62 consecutive adult patients. Mayo Clin Proc 2009; 84: 417-21. [CrossRef]

4. Fathi M, Vikgren J, Boijsen M, Tylen U, Jorfeldt L, Tornling G, et al. Interstitial lung disease in polymyositis and dermatomyositis: longitudinal evaluation by pulmonary function and radiology. Arthritis Rheum 2008; 59: 677-85. [CrossRef]

5. Kang EH, Lee EB, Shin KC, Im CH, Chung DH, Han SK, et al. Interstitial lung disease in patients with polymyositis, dermatomyositis and amyopathic dermatomyositis. Rheumatology (Oxford) 2005; 44: 1282-6. [CrossRef]

6. Le Goff B, Chérin P, Cantagrel A, Gayraud M, Hachulla E, Laborde F, et al. Pneumomediastinum in interstitial lung disease associated with dermatomyositis and polymyositis. Arthritis Rheum 2009; 61: 108-18. [CrossRef]

7. Korkmaz C, Ozkan R, Akay M, Hakan T. Pneumomediastinum and subcutaneous emphysema associated with dermatomyositis. Rheumatology (Oxford) 2001; 40: 476-8. [CrossRef]

8. Yoshida K, Kurosaka D, Kingetsu I, Hirai K, Yamada A. Pneumomediastinum in dermatomyositis itself is not a poor prognostic factor: report of a case and review of the literature. Rheumatol Int 2008; 28: 913-7. [CrossRef]

9. Terao $\mathrm{M}$, Ozawa $\mathrm{K}$, Inui $\mathrm{S}$, Murota $\mathrm{H}$, Yokomi A, Itami S. A case of dermatomyositis complicated with pneumomediastinum. Mod Rheumatol 2007; 17: 156-9. [CrossRef]

10. Cicuttini FM, Fraser KJ. Recurrent pneumomediastinum in adult dermatomyositis. J Rheumatol 1989; 16: 384-6.

11. Yamanishi Y, Maeda H, Konishi F, Hiyama K, Yamana S, Ishioka S, et al. Dermatomyositis associated with rapidly progressive fatal interstitial pneumonitis and pneumomediastinum. Scand J Rheumatol 1999; 28: 58-61. [CrossRef]

12. Kono $\mathrm{H}$, Inokuma $\mathrm{S}$, Nakayama $\mathrm{H}$, Suzuki M. Pneumomediastinum in dermatomyositis: association with cutaneous vasculopathy. Scand J Rheumatol 1999; 28: 58-61.

13. Neves Fde S, Shinjo SK, Carvalho JF, Levy-Neto M, Borges CT. Spontaneous pneumomediastinum and dermatomyositis may be a not so rare association: report of a case and review of the literature. Clin Rheumatol 2007; 26: 105-7. [CrossRef] 
14. Ma X, Chen Z, Hu W, Guo Z, Wang Y, Kuwana M, et al. Clinical and serological features of patients with dermatomyositis complicated by spontaneous pneumomediastinum. Clin Rheumatol 2015; Jul 7. [Epub ahead of print]

15. Zhang L, Shen M, Zhang F, Tang F. Survival analysis and risk factors for mortality in connective tissue disease-associated pneumomediastinum. Rheumatol Int 2014; 34: 1657-63. [CrossRef]

16. Kim HJ, Hong YK, Yoo WH. Dermatomyositis, complicated with pneumomediastinum, successfullytreated with cyclosporine A: a case report and review of literature. Rheumatol Int 2009; 29: 1101-4. [CrossRef]
17. Matsuoka S, Kurihara Y, Yagihashi K, Okamoto K, Niimi H, Nakajima Y. Thin-section CT assessment of spontaneous pneumomediastinum in interstitial lung disease: correlation with serial changes in lung parenchymal abnormalities. Respir Med 2006; 100: 11-9. [CrossRef]

18. Yamasaki Y, Yamada H, Yamasaki M, Ohkubo M, Azuma K, Matsuoka S, et al. Intravenous cyclophosphamide therapy for progressive interstitial pneumonia in patients with polymyositis/dermatomyositis. Rheumatology (Oxford) 2007; 46: 124-30. [CrossRef]

19. Kim SH, Huh J, Song J, Kang IS. Spontaneous Pneumomediastinum: A Rare Disease Associated with Chest Pain in Adolescents. Yonsei Med J 2015; 56: 1437-42. [CrossRef] 